6 - ORIGINAL ARTICLE

ISCHEMIA-REPERFUSION

\title{
Effect of protective solutions and hydroxyethyl starch in the attenuation of the injuries of ischemia and reperfusion of splanchnic organs ${ }^{1}$
}

\author{
Marcelo Eduardo Ribeiro ${ }^{\text {, Julio Sequeira }}{ }^{\mathrm{II}}$, Luzia Aparecida Trinca ${ }^{\mathrm{III}}$, Winston Bonetti Yoshida ${ }^{\mathrm{IV}}$ \\ DOI: http://dx.doi.org/10.1590/S0102-865020150060000006 \\ IFellow Master degree, Postgraduate Program in Surgery on General Basis of Surgery, Department of Surgery and Orthopedics, Botucatu School \\ of Medicine, Paulista State University (UNESP), Botucatu-SP, Brazil. Intellectual, scientific content and design of the study; technical procedures; \\ manuscript preparation.

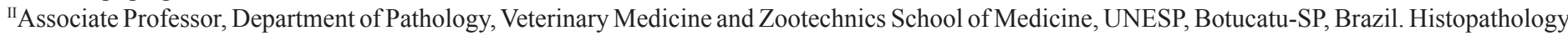 \\ examinations. \\ IIIAssociate Professor, Department of Statistics, Biosciences Institute, UNESP, Botucatu-SP, Brazil. Statistical analysis.

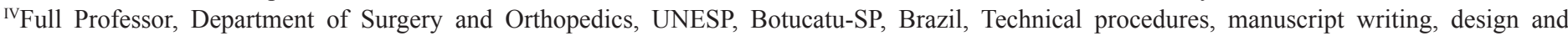 \\ supervised all phases of the study.
}

\section{ABSTRACT}

PURPOSE: Vogt's antioxidant solution (red blood cells, Ringer's solution, sodium bicarbonate, mannitol, allopurinol and 50\% glucose) or its modification including hydroxyethyl starch (HES) were tested for the prevention of splanchnic artery occlusion shock.

METHODS: Seventy rats were distributed in treatment (3), control (1), and sham (3) groups. Ischemia and reperfusion were induced by celiac, superior mesenteric and inferior mesenteric arteries occlusion for $40 \mathrm{~min}$, followed by $60 \mathrm{~min}$ reperfusion or sham procedures. Controls received saline, both treatment and sham groups received the Vogt's solution, modified Vogt's solution (replacing Ringer's solution by HES), or HES. Mean arterial blood pressure (MABP), ileal malondialdehyde (MDA) and plasmatic MDA were determined, and a histologic grading system was used.

RESULTS: At reperfusion, MABP dropped in all I/R groups. Only HES treatment was able to restore final MABP to the levels of sham groups. Plasmatic MDA did not show differences between groups. Ileum MDA was significantly higher in the control and treatment groups as compared to the sham group. Histology ranking was higher in the only in control group.

CONCLUSIONS: Hydroxyethyl starch was able to prevent hemodynamic shock but not intestinal lesions. Both treatments with Vogt's solutions did not show any improvement.

Key words: Ischemia. Reperfusion. Protective Agents. Hydroxyethyl Starch Derivatives. Free Radicals. Antioxidants. Rats. 


\section{Introduction}

Mesenteric ischemia is still associated with high mortality rates, which are related to the ischemia and reperfusion of the splanchnic organs ${ }^{1}$. The main clinical adverse consequence is a severe circulatory collapse known as splanchnic artery occlusion shock - SAOS ${ }^{2,3}$. Increased capillary permeability ${ }^{4}$, accumulation of oxygen-derived free radicals ${ }^{5}$, and alteration of the intestinal barrier $^{6}$ are the main contributors to the development of this syndrome.

The role of free radicals in splanchnic ischemia and reperfusion shock is well established ${ }^{7,8}$. Since exogenous administration of antioxidants may aid in increasing the tolerance to or in ameliorating the effects of ischemia and reperfusion injury $^{9-11}$, this study was designed to assess the role of a protective antioxidant solution (red blood, cells, Ringer's solution, sodium bicarbonate, mannitol, allopurinol and 50\% glucose) used by Vogt et al. ${ }^{12}$ in acute aortic occlusion, in comparison to its modification including hydroxyethyl starch, in the prevention of splanchnic artery occlusion shock (SAOS $)^{13,14}$, using an experimental model.

\section{Methods}

This experiment followed the Council for International Organization of Medical Sciences (CIOMS) ethical code for animal experimentation and was approved by the Ethics in Research Committee (Protocol 22/99).

An experimental animal model of splanchnic ischemia and reperfusion was used in 70 male Wistar nonfasted rats weighing 250-350g, which were anesthetized with intraperitoneal sodium pentobarbital $(30 \mathrm{mg} / \mathrm{kg})$ and supplements of pentobarbital given as necessary at the dosage of $10 \mathrm{mg} / \mathrm{kg}$ intramuscular. The trachea was exposed and cannulated with a 14-gauge catheter. A 22-gauge catheter was inserted into the left carotid artery and connected to a pressure transducer. A 22-gauge catheter was inserted into the right jugular vein for the solutions injections.

A midline abdominal incision was used to access the visceral arteries. The celiac, superior mesenteric and inferior mesenteric arteries were exposed and encircled with vessel loops. Intravenous heparin (100 IU/kg) was administered during the 20 min stabilization period, at the conclusion of which a microvascular clamp was placed on each visceral artery for 40 min in order to produce splanchnic ischemia, except in the sham groups (Figure 1). The clamps were then removed and the mean arterial blood pressure was recorded for an additional $60 \mathrm{~min}$, designated as the reperfusion period. The viscera were kept in the cavity throughout the experiment.
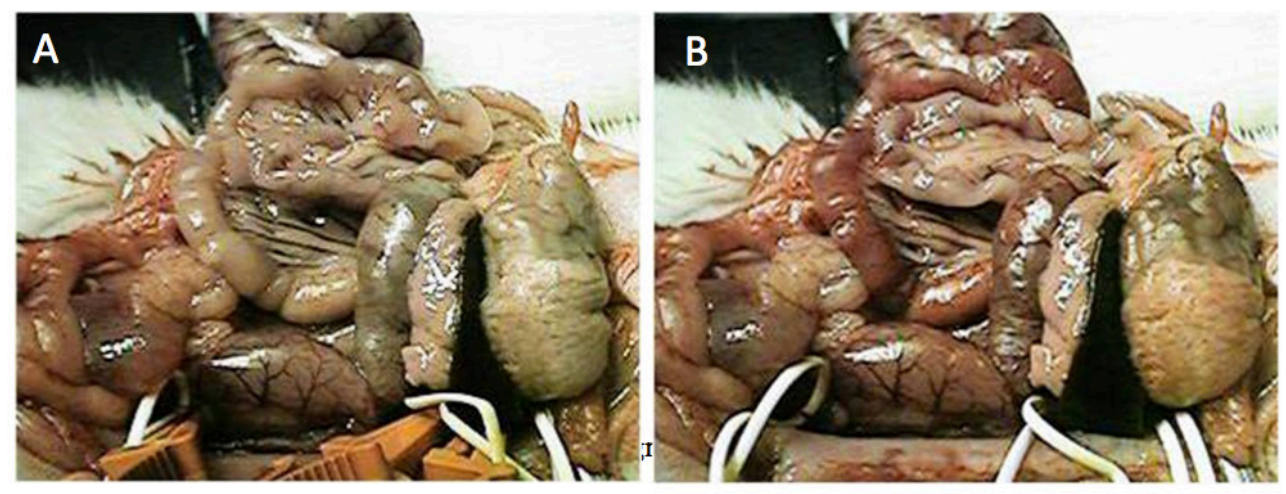

FIGURE 1 - Experimental rat model. Visceral appearance after ischemia (A) and reperfusion (B) in a similar experimental setting.

The rats were allocated at random to seven groups of ten animals each:

The rats were distributed in seven groups:

Group 1 (Control): the rats received continuous saline $(0.9 \mathrm{NaCl}, 4 \mathrm{ml} / \mathrm{kg} /$ hour$)$, starting at the occlusion of the visceral arteries;

Group 2 (Sham 1): the rats received continuous saline $(0.9 \% \mathrm{NaCl}, 4 \mathrm{ml} / \mathrm{kg} /$ hour$)$, and subsequently underwent all surgical steps of controls except for the occlusion of the visceral arteries;

Group 3 (Sham 2): the rats received continuous Vogt's solution ( $4 \mathrm{ml} / \mathrm{kg} /$ hour), and subsequently underwent all surgical steps of controls except for the occlusion of the visceral arteries (Table 1);

Group 4 (Sham 3): the rats received continuous modified Vogt's solution (4 ml/kg/hour), and subsequently underwent all 
surgical steps of controls except for the occlusion of the visceral arteries (Table 1);

Group 5 (Vogt's solution): the rats received continuous Vogt's solution ( $4 \mathrm{ml} / \mathrm{kg} /$ hour), and surgery and occlusion of the visceral arteries were performed as in the control group;

Group 6 (Modified Vogt's solution): the rats received continuous modified Vogt's solution ( $4 \mathrm{ml} / \mathrm{kg} /$ hour), and surgery and occlusion of the visceral arteries were performed as in the control group;

Group 7 (Hydroxyethyl starch): the rats received continuous hydroxyethyl starch $(4 \mathrm{ml} / \mathrm{kg} /$ hour $)$, and surgery and occlusion of the visceral arteries were performed as in the control group.

TABLE 1 - Components of the Vogt's12 and modified solution.

\begin{tabular}{lcc}
\hline Components & Vogt's $^{\mathbf{1 2}}$ solution & Modified sol \\
\hline Red blood cells & $10 \mathrm{~mL}$ & $10 \mathrm{~mL}$ \\
Ringer's solution & $01 \mathrm{~mL}$ & - \\
Sodium bicarbonate $8.4 \%$ & $03 \mathrm{~mL}$ & $03 \mathrm{~mL}$ \\
Mannitol 20\% & $01 \mathrm{~mL}$ & $01 \mathrm{~mL}$ \\
Allopurinol & $01 \mathrm{~mL}$ & $01 \mathrm{~mL}$ \\
Glucose 50\% & $01 \mathrm{~mL}$ & $01 \mathrm{~mL}$ \\
Hydroxyethyl starch & - & $03 \mathrm{~mL}$
\end{tabular}

OBS: Blood cells were collected from normal rats of the same flock, with no processing.

\section{Parameters}

\section{A. Mean arterial blood pressure}

A 22-gauge catheter was inserted into the left carotid artery and connected to a pressure transducer (Biopac model MP-100) for continuous measurement of the mean arterial blood pressure. Results were displayed in a computer and recorded at 10 min intervals.

\section{B. Plasmatic malondialdehyde determination}

At the conclusion of reperfusion (60 $\mathrm{min})$, the animals were sacrificed by means of an intra-arterial injection of potassium chloride. Blood was then collected and frozen in liquid nitrogen for a later TBARS analysis (Thiobarbituric acid reactive substances), using the technique by Satoh et $a l .{ }^{15}$. In short, serum was added to trichloroacetic acid and thiobarbituric acid in a hot environment for $30 \mathrm{~min}$. Chromogen was extracted by n-butanol. After centrifugation, absorbance was read at a wavelength of $530 \mathrm{~nm}$. Values were expressed in nanomoles of MDA per ml.

\section{Ileal malondialdehyde determination}

At the conclusion of reperfusion (60 $\mathrm{min})$, an ileum segment was removed, and the section was rinsed in saline and frozen in liquid nitrogen for TBARS analysis, with the same technique used for blood analysis ${ }^{15}$. In short, tissue sample was homogenized for $30 \mathrm{~min}$ and a homogenized sample $(2.5 \mathrm{ml})$ was added to trichloroacetic acid and thiobarbituric acid. Similar steps to analyze blood MDA were then followed. Values were expressed in nanomoles of MDA per mg.

\section{Histopathology}

Another ileal segment was rinsed in saline and placed into $10 \%$ buffered formaldehyde. Ileal sections were processed with standard hematoxylin and eosin staining for light microscopy. For comparative histologic analysis a sixlevel ranking system ${ }^{16}$ was utilized: grade $0=$ normal; grade $1=$ exfoliation of superficial mucosal cells but no necrosis; grade 2 $=$ necrosis of mucosal villi with preservation of crypts; grade $3=$ mucosal necrosis including crypts; grade $4=$ complete mucosal necrosis with thinning of muscularis mucosae or necrosis of inner layer of muscularis mucosae; and grade $5=$ transmural necrosis (Figure 2). A pathologist blinded to the sample groups performed grading.
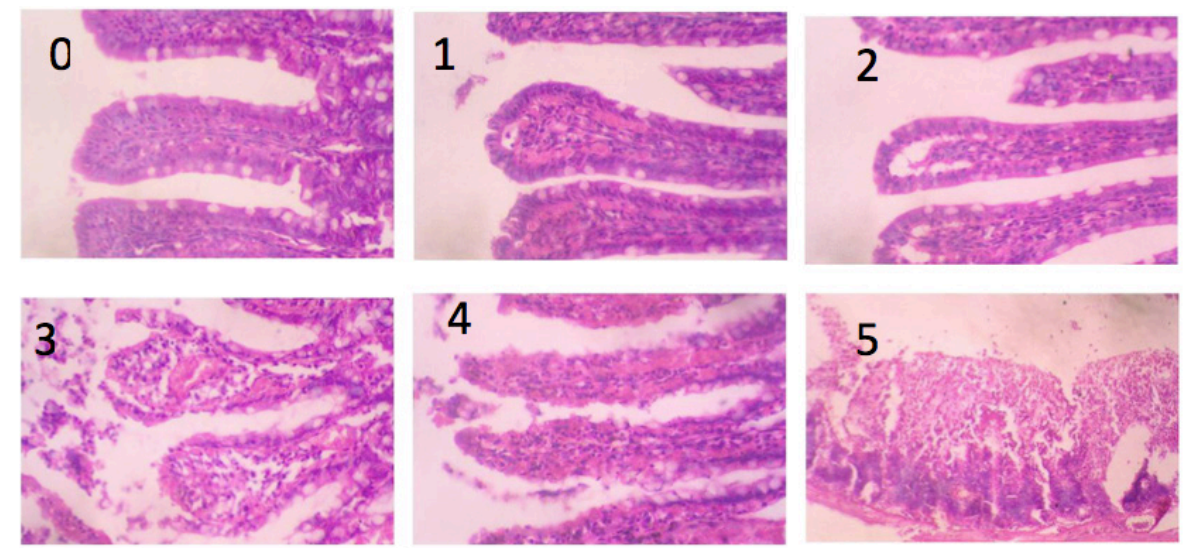

FIGURE 2 - Examples of the experimental setup using Chiu et al. ${ }^{17}$ histological grading system. 


\section{E. Statistical analysis}

The level of significance adopted was 5\%. The KruskalWallis test was used to perform the statistical comparisons of the histological studies. For the other parameters multivariate analysis of variance (profile analysis) was used. The level of significance adopted was $5 \%$.

\section{Results}

Mean arterial blood pressure of the Sham group 2 remained constant and groups 3 and 4 had a slight but not significant decrease along the experiment. The other groups exhibited comparable mean arterial blood pressures during the stabilization and ischemic periods. During reperfusion, however, there was a marked decrease of arterial blood pressures, with partial recovery in groups 5 and 6, and total recovery only in group 7. Statistical analysis demonstrated that final mean arterial blood pressures in group 7 were similar to the Sham groups (group G2, G3 and G4) and higher than in the control group (group 7). Final mean arterial blood pressure of groups 5 and 6 were similar to the control group and were significantly lower than in the sham groups (Figure 3).

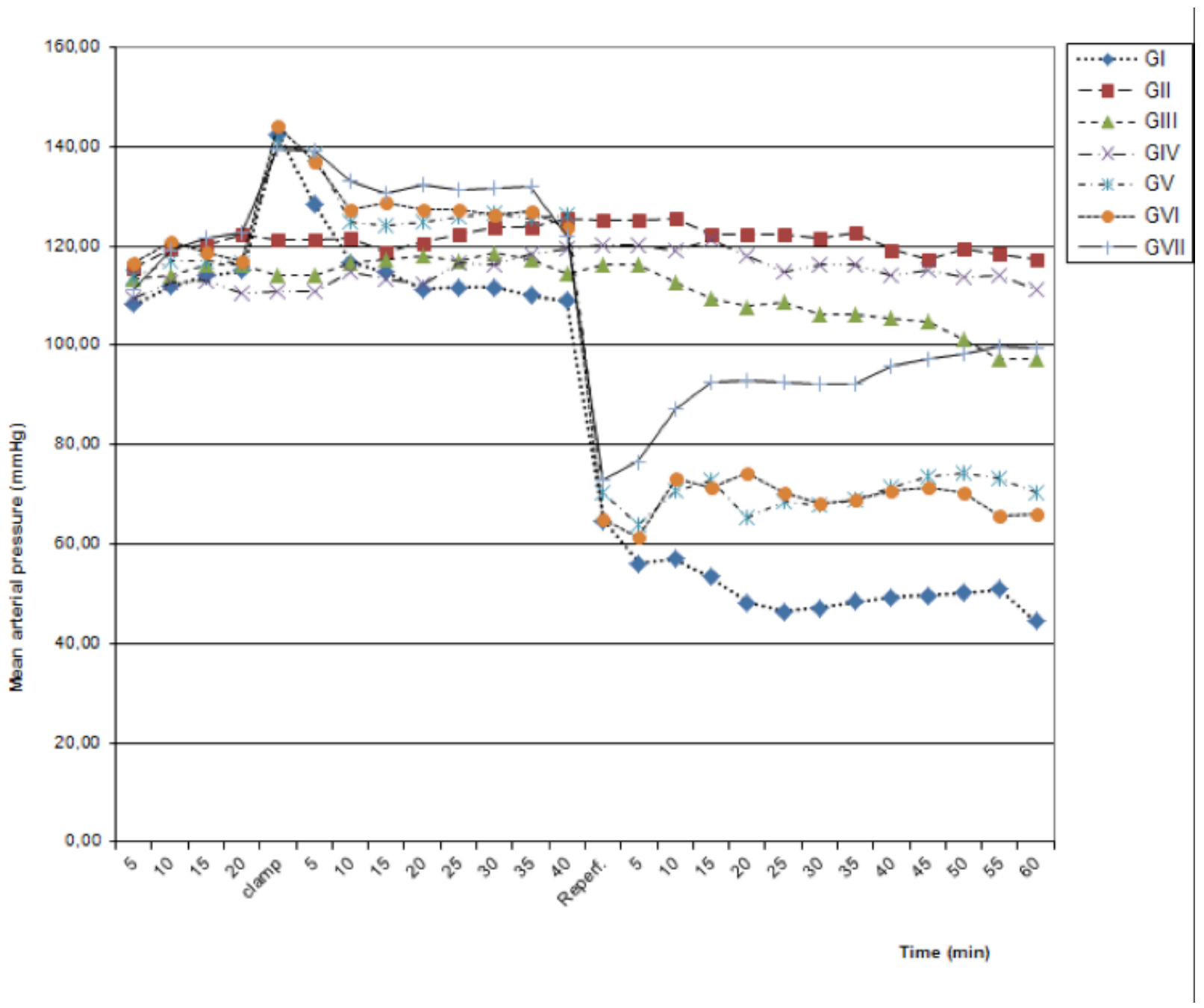

FIGURE 3 - Mean arterial pressure $(\mathrm{mmHg})$ along the experiment.

There was no significant difference of plasma MDA between group 1 and groups 2, 3, 4, 6, and 7. Group 5 presented a significantly higher MDA in blood, compared to the others groups.

Statistical analysis showed that the ileum MDA of group 1 (Control) was significantly higher than in group 3. Ileum MDA of the treatment groups (groups G5, G6 and G7) were similar among them and among the sham groups (groups G2, G3 and G4). Mean values of the sham groups were significantly lower than of the control group (group 1) and of treatment groups (G5, G6 and G7) (Table 2). 
TABLE 2 - Results of biochemical parameters $(\mathrm{Mean} \pm \mathrm{SD})$ in each group.

\begin{tabular}{lcc}
\hline \multirow{2}{*}{ Groups } & \multicolumn{2}{c}{ Parameters } \\
\cline { 2 - 3 } & Plasma MDA $(\mathrm{nMol} / \mathrm{mL})$ & Ileum MDA (nMol/mg) \\
\hline Group 1 & $9.365 \pm 3.021$ & $5.91 \pm 0.88$ \\
Group 2 & $8.675 \pm 2.031^{*}$ & $4.29 \pm 1.47$ \\
Group 3 & $7.710 \pm 1.270$ & $3.33 \pm 0.91 *$ \\
Group 4 & $9.195 \pm 4.876$ & $4.14 \pm 1.64$ \\
Group 5 & $15.855 \pm 6.208 *$ & $5.37 \pm 1.76$ \\
Group 6 & $10.800 \pm 2.061$ & $5.55 \pm 1.30$ \\
Group 7 & $6.905 \pm 1.008$ & $5.77 \pm 1.40$ \\
\hline $\mathrm{p}$ & $* \mathrm{p}<0.05$ & $* \mathrm{p}<0.05$ \\
\hline
\end{tabular}

The study of the ileum histology showed that the sham group (groups $2,3,4$ ) results were similar to the groups 5,6 , and 7. The median of the control group was significantly higher than those of the sham groups (Figure 4).

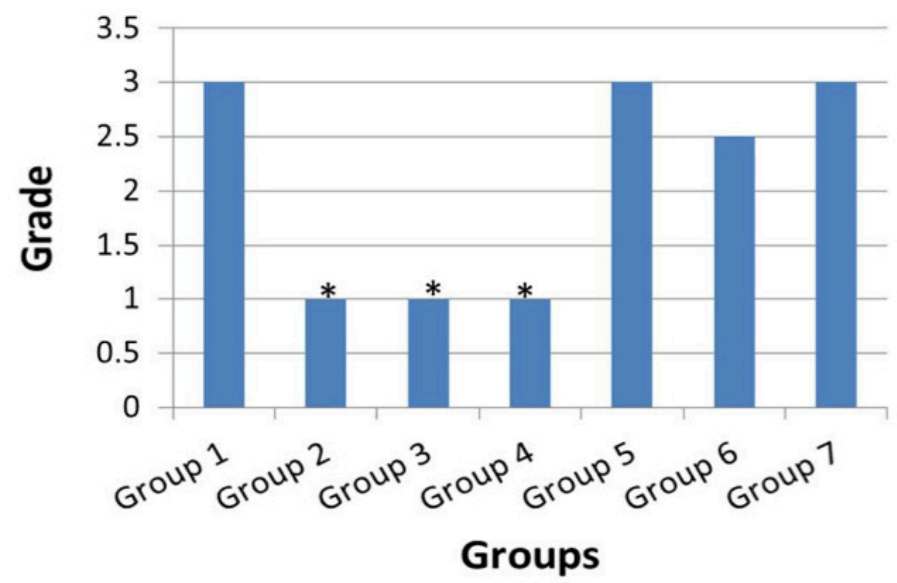

FIGURE 4 - Median of ileum histological classification according to Chiu et al. ${ }^{17} \cdot{ }^{*} \mathrm{p}<0.05$.

\section{Discussion}

Splanchnic artery occlusion shock (SAOS) is a common clinical problem related to ischemia and reperfusion of splanchnic organs. This shock can be consistently reproduced in a rat model using the same ischemic and reperfusion times of our previous similar experimental settings ${ }^{3,10}$. Many local and systemic modifications are involved in the development of this syndrome, the release of oxygen-derived free-radicals being very important and extensively studied ${ }^{3}$. During reperfusion there is a heavy production of free-radicals and the efficacy of the endogenous scavengers is not only compromised, but also decreased quantitatively inside the cell ${ }^{17}$. Based on these evidences, several authors decided to investigate the treatment of the consequences of splanchnic organs ischemia and reperfusion with the administration of exogenous scavenger. The results obtained were quite variable, and since no single approach has proven consistently effective in limiting damage of ischemia and reperfusion, it has been suggested that a "cocktail" of scavengers might be necessary to eliminate all toxic oxygen species. Vogt et al. ${ }^{12}$ used a protective solution (cocktail) with crystalloids (for volume supply), blood ( for oxygen supply to the ischemic tissues), glucose (for energy supply) and two antioxidants: mannitol (hydroxyl scavenger) and allopurinol (xanthine inhibitor). The use of this solution during aortic occlusion for aortic surgery was capable of preventing shock as well as visceral and limb damage during reperfusion. In other $\operatorname{articles}^{13,14,18-20}$, the use of HES in a rat experimental model of splanchnic organs ischemia and reperfusion, was capable of significantly attenuating hemodynamic shock. So, it seemed reasonable to us that the substitution of the Ringer's solution in the Vogt's "cocktail" by HES could improve the results in SAOS.

Curiously, the results of the present study did not show any improvement with either Vogt's ${ }^{12}$ or modified Vogt's solutions and the best result was achieved with HES alone.

It has been suggested that the macromolecules of HES could act as a sealant of endothelial gaps, preventing fluid loss and improving the hemodynamic stability ${ }^{20}$. During splanchnic ischemia and reperfusion there is an opening of the inter-endothelial spaces, caused by cellular contraction, rupture of endothelial junctions, or increased porosity of the endothelial surface ${ }^{18}$. These changes may be caused by the release of inflammatory mediators, hypoxia, alteration in lymphatic flow or accumulation of toxic metabolites ${ }^{8,21}$. The use of HES could bring interstitial fluid back to the intravascular space, reducing stasis and interstitial edema, and establishing lymphatic flow and perfusion. Therefore, the occlusion of cellular orifices and intercellular spaces associated to oncotic pressure increased by HES, constituted a barrier against fluid loss, attenuating the circulatory shock in the experimental model used in the present study.

Neither original nor modified Vogt's solutions were able to restore mean arterial blood pressure to the levels of sham groups. However, their results were better than those of the control group. It may have been, therefore, that the antioxidants present in their composition were able to partially improve the MABP. The volume infused ( $4 \mathrm{ml} / \mathrm{kg} /$ hour) was based in previous experiments by our group and a pilot study ${ }^{10,14}$, however, with addition of HES there was a general dilution of the original Vogt's solution, what might have decreased the action of the separate components.

Complications of HES in clinical practice are mainly related to dosage and clinical situation ${ }^{22}$. In the present experimental setting, the HES dosage was comparatively lower and it was used as a positive control. 
Although MAPB was totally restored by HES and partially improved by Vogt's solutions, the histology rankings of these groups were similar to control, demonstrating that the improvement in hemodynamics was not accompanied by intestinal protection. These results suggest that the intestinal lesion was very severe in this experimental model, and that something else other than just improvement in hemodynamics would be necessary to protect the intestines.

Plasma MDA and ileal lipid hydroperoxides determinations were variable results and would reflect metabolization or dispersion of these substances in the period studied. The ileal MDA was a little less variable, with increased results in the control group and treatment groups, as compared to sham groups. These results suggest that the antioxidant therapy employed was not capable of producing products of membrane lipid peroxidation in the ileal tissue.

\section{Conclusions}

Hydroxyethyl starch could prevent hemodynamic shock but not intestinal injury. Neither original nor modified Vogt's solutions showed any improvement at all.

\section{References}

1. Slone EA, Fleming SD. Membrane lipid interactions in intestinal ischemia/reperfusion-induced injury. Clin Immunol. 2014;153:22840. doi: 10.1016/j.clim.2014.04.018.

2. Crisafulli C, Mazzon E, Galuppo M, Paterniti I, Caminiti R, Cuzzocrea S. Olprinone attenuates the development of ischemia/ reperfusion injury of the gut. Intensive Care Med. 2010;36:1235-47. doi: 10.1007/s00134-010-1798-4.

3. Cerqueira NF, Hussni CA, Yoshida WB, Padovani CR. Systemic evaluation on ischemia and reperfusion injury of splanchnic organs in rats. Acta Cir Bras. 2009;24:290-5. doi: S010286502009000400008.

4. Cerqueira NF, Yoshida WB. Óxido nítrico: revisão. Acta Cir Bras. 2002;17:417-23. doi: 10.1590/S0102-86502002000600011.

5. Schoenberg MH, Beger HG. Oxygen radicals in intestinal ischemia and reperfusion. Chem Biol Interact. 1990;76:141-61. PMID: 1707389.

6. Wang X, Pan L, Lu J, Li N, Li J. N-3 PUFAs attenuate ischemia/ reperfusion induced intestinal barrier injury by activating I-FABPPPARgamma pathway. Clin Nutr. 2012;31:951-7. doi: 10.1016/j. clnu.2012.03.003.

7. Zhao W, Gan X, Su G, Wanling G, Li S, Hei Z, Yang C, Wang H. The interaction between oxidative stress and mast cell activation plays a role in acute lung injuries induced by intestinal ischemia-reperfusion. J Surg Res. 2014;187:542-52. doi: 10.1016/j.jss.2013.10.033.

8. Ribeiro ME, Yoshida WB. Lesões intestinais decorrentes de isquemia e reperfusão: fisiopatologia e modelos experimentais. J Vasc Bras. 2005;4:183-94.

9. Yoshida WB, Alasio T, Mazziotta R, Qin F, Kashani M, Lee S, Dardik $\mathrm{H}$, Becker R. Effect of alpha-tocopherol, taurine and selenium on the attenuation of ischemia/reperfusion injury of splanchnic organs. Cardiovasc Surg. 1998;6:178-87. PMID: 9610832.

10. Cerqueira NF, Hussni CA, Yoshida WB, Sequeira JL, Padovani CR. Effects of pentoxifylline and n-acetylcysteine on injuries caused by ischemia and reperfusion of splanchnic organs in rats. Int Angiol. 2008;27:512-21. PMID: 19078915.

11. Yoshida WB, Campos EB. Ischemia and reperfusion in skin flaps: effects of mannitol and vitamin $\mathrm{C}$ in reducing necrosis area in a rat experimental model. Acta Cir Bras. 2005;20:358-63. PMID: 16186959.

12. Vogt PR, von Segesser LK, Pagotto E, Lijovic T, Turina MI. Simplified, controlled limb reperfusion and simultaneous revascularization for acute aortic occlusion. J Vasc Surg. 1996;23:730-3. PMID: 8627914.

13. Oz MC, Zikria BA, McLeod PF, Popilkis SJ. Hydroxyethyl starch macromolecule and superoxide dismutase effects on myocardial reperfusion injury. Am J Surg. 1991;162:59-62. PMID: 1712154.

14. Macarenco RS, Takahagi RU, Bardella LC, Sequeira JL, Yoshida WB. Estudo da açäo do extrato de Ginkgo biloba e amido hidroxietílico hipertônico na atenuaçäo de alteraçöes decorrentes de isquemia e reperfusäo de órgäos esplâncnicos em ratos. Acta Cir Bras. 2001;16:139-45.

15. Satoh K. Serum lipid peroxide in cerebrovascular disorders determined by a new colorimetric method. Clin Chim Acta. 1978;90:37-43. PMID: 719890.

16. Chiu CJ, McArdle AH, Brown R, Scott HJ, Gurd FN. Intestinal mucosal lesion in low-flow states. I. A morphological, hemodynamic, and metabolic reappraisal. Arch Surg. 1970;101:478-83. PMID: 5457245 .

17. Myers SI, Hernandez R. Oxygen free radical regulation of rat splanchnic blood flow. Surgery. 1992;112:347-54. PMID: 1641774.

18. Simonian G, Dardik H, Hallac D, Ibrahim I, Stahl R. Pharmacologic amelioration of splanchnic arterial occlusion shock and reperfusion injury: comparative studies of microvascular permeability and free radical toxicity in a rat model. Vasc Surg. 1997;31:645-56.

19. Li XL, Zou X, Nie G, Song ML, Li G, Cui W. Role of hydroxyethyl starch in ischemia-reperfusion injury in rat intestinal transplantation. Transplant Proc. 2013;45:2491-6. doi: 10.1016/j. transproceed.2013.02.133.

20. Wisselink W, Patetsios P, Panetta TF, Ramirez JA, Rodino W, Kirwin JD, Zikria BA. Medium molecular weight pentastarch reduces reperfusion injury by decreasing capillary leak in an animal model of spinal cord ischemia. J Vasc Surg. 1998;27:109-16. PMID: 9474088

21. Camara-Lemarroy CR, Guzman-de la Garza FJ, Cordero-Perez P, Alarcon-Galvan G, Ibarra-Hernandez JM, Munoz-Espinosa LE, Fernandez-Garza NE. Bupropion reduces the inflammatory response and intestinal injury due to ischemia-reperfusion. Transplant Proc. 2013;45:2502-5. doi: 10.1016/j.transproceed.2013.04.010.

22. Serpa Neto A, Veelo DP, Peireira VG, de Assuncao MS, Manetta JA, Esposito DC, Schultz MJ. Fluid resuscitation with hydroxyethyl starches in patients with sepsis is associated with an increased incidence of acute kidney injury and use of renal replacement therapy: a systematic review and meta-analysis of the literature. J Crit Care. 2014;29:185 e1-7. PMID: 24262273.

\section{Correspondence:}

Winston Bonetti Yoshida

Departamento de Cirurgia e Ortopedia

Faculdade de Medicina de Botucatu-UNESP

Campus de Botucatu 
Effect of protective solutions and hydroxyethyl starch in the attenuation of the injuries of ischemia and reperfusion of splanchnic organs

Tel.: (55 14)3880-1443

winston@fmb.unesp.br

Received: Feb 12, 2015

Review: Apr 14, 2015

Accepted: May 13, 2015

Conflict of interest: none

Financial source: Sao Paulo Research Foundation (FAPESP, process $n^{\circ}$ 97/04647-4)

${ }^{1}$ Research performed at Experimental Laboratory, Department of Surgery and Orthopedics, Botucatu School of Medicine, Paulista State University (UNESP), Botucatu-SP, Brazil. 